\section{Response to 'Decision making value of nuclear dense fine speckled pattern in systemic autoimmune rheumatic disease: trick or treat?' by Deng et al}

The correspondence of Deng et $a l^{1}$ raises practical issues regarding the recognition and clinical interpretation of the nuclear dense fine speckled (DFS, AC-2) pattern in a typical clinical immunology laboratory during antinuclear antibody (ANA) screening using indirect immunofluorescence assay on HEp-2 cells (HEp-2 IIFA). Based on the recommendation of the International Consensus on ANA Patterns (ICAP), ${ }^{2}$ the recognition of a nuclear DFS pattern is not to be taken as the same as the determination of an anti-DFS70 antibody using a follow-up specific immunoassay. In fact, HEp-2 IIFA is a screening test for a vast array of autoantibodies and is not intended for the final determination of autoantibody specificity. Accordingly, the ICAP recommendation is clear that all HEp-2 IIFA patterns as defined by ICAP, with the sole exception of anti-centromere (AC-3), must be followed-up with specific immunoassays. ${ }^{2}$ With specific regard to the AC-2 pattern, a recent review article has clearly pointed out that anti-DFS70 antibodies must be defined by specific immunoassays and not by HEp-2 IIFA alone. ${ }^{3}$ Currently, the alternative methods for determining reactivity to DFS70 include ELISA, chemiluminescent immunoassays, and variations of the HEp-2 IIFA (either after immune absorption against DFS70 antigen or using DFS70 knockout cells). However, a low agreement rate has been reported between some of these methods, ${ }^{4}$ implicating further research is needed in optimising the detection method/strategy. The recent availability of an international anti-DFS70 reference material distributed by the Autoantibody Standardization Committee (http://www.autoab.org) should contribute in the harmonisation of these immunoassays towards improvement in the agreement rate. ${ }^{5}$

A related issue is the clinical relevance of the DFS pattern and anti-DFS70 antibodies. There has been progressive clarification on the clinical significance of anti-DFS70 antibodies since the original report on the association with interstitial cystitis in $1994 .^{6}$ It is now established that anti-DFS70, when present alone in the sample, occurs in 1\%-9\% of the general population worldwide. ${ }^{7}$ It occurs in a similar frequency also in systemic autoimmune diseases but is usually associated with disease-specific autoantibodies. Therefore, the negative association of anti-DFS70 antibodies with systemic autoimmunity is valid only if other disease-specific autoantibodies are ruled out. It happens that the bona fide DFS pattern is clearly apparent when anti-DFS70 is the only autoantibody in the sample, as the staining pattern derived from other autoantibodies tend to interfere with the typical DFS pattern. In that sense, the correct identification of the DFS pattern serves as a preliminary proxy to the existence of a pure anti-DFS70 antibody in the sample. However, as mentioned before, this must be confirmed in specific immunoassays. This should not result in a significant delay in the final clinical decision as these tests are amenable to be available in regular clinical immunology laboratories; however, some restrictions may apply to certain countries at this time.

It is surprising that Deng et al had only 58 samples with the DFS pattern (2.3\%) out of 2,507 HEp-2 IIFA positive samples. ${ }^{1}$ In our experience, the DFS pattern is one of the most commonly observed patterns, accounting for $37 \%$ of 13
641 sequential HEp-2 IIFA-positive samples in a large clinical laboratory. ${ }^{8}$ Although ethnical and environmental factors may influence the prevalence of anti-DSF70 antibodies, it is recognised that the definition of the DFS pattern is subjective and amenable to misclassification. ${ }^{9}$ In fact, a variety of slightly different patterns sharing the properties of nuclear fine speckled staining and similar staining of the mitotic chromatin may be misinterpreted as the DFS pattern. These DFS-like patterns, being confirmed anti-DFS70 antibody negative, have been recently referred to as pseudo-DFS patterns ${ }^{10}$ and are the focus of an ongoing study by ICAP members. Among patients with pseudo-DFS patterns, there may be some with systemic autoimmune diseases. Since Deng et al have not determined anti-DFS70 reactivity in specific immunoassays, it is possible that cases of pseudo-DFS pattern may have contributed to the high frequency of systemic autoimmune diseases in their cohort.

\section{Luis Eduardo Coelho Andrade, ${ }^{1}$ Jan Damoiseaux, ${ }^{\oplus 2}$ Edward K Chan ${ }^{3}$}

${ }^{1}$ Rheumatology Division, Universidade Federal de Sao Paulo, Sao Paulo, Brazil

${ }^{2}$ Maastricht University Medical Centre, Maastricht, The Netherlands

${ }^{3}$ Department of Oral Biology, University of Florida, Gainesville, Florida, USA

Correspondence to Dr Jan Damoiseaux, Maastricht University Medical Center, Maastricht 6229 HX, Netherlands; jan.damoiseaux@mumc.nl

Handling editor Josef S Smolen

Acknowledgements The authors acknowledge the contribution of all members of the ICAP executive board.

Funding This research received no specific grant from any funding agency in the public, commercial or not-for-profit sectors.

Competing interests None declared.

Patient consent for publication Not required.

Provenance and peer review Commissioned; internally peer reviewed.

(C) Author(s) (or their employer(s)) 2019. No commercial re-use. See rights and permissions. Published by BMJ.

\section{Check for updates}

To cite Andrade LEC, Damoiseaux J, Chan EK. Ann Rheum Dis Epub ahead of print: [please include Day Month Year]. doi:10.1136/annrheumdis-2019-215640

Received 6 May 2019

Accepted 6 May 2019

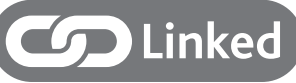

- http://dx.doi/org/10.1136/annrheumdis-2019-215587

Ann Rheum Dis 2019;0:1-2. doi:10.1136/annrheumdis-2019-215640

\section{REFERENCES}

1 Deng C, Qu X, Cheng S, et al. Decision making value of nuclear dense fine Speckled pattern in systemic autoimmune rheumatic diseaseL trick or treat? Ann Rheum Dis 2019.

2 Damoiseaux J, Andrade LEC, Carballo OG, et al. Clinical relevance of HEp-2 indirect immunofluorescent patterns: the International consensus on ANA patterns (ICAP) perspective. Ann Rheum Dis 2019.

3 Mahler M, Andrade LE, Casiano CA, et al. Anti-DFS70 antibodies: an update on our current understanding and their clinical usefulness. Expert Rev Clin Immunol 2019:15:241-50.

4 Infantino M, Shovman O, Pérez D, et al. A better definition of the anti-DFS70 antibody screening by IIF methods. J Immunol Methods 2018;461:110-6.

5 Dellavance A, Baldo DC, Zheng B, et al. Establishment of an international autoantibody reference standard for human anti-DFS70 antibodies: proof-of-concept study for a novel Megapool strategy by pooling individual specific sera. Clin Chem Lab Med 2019. doi:10.1515/cclm-2019-0087

6 Ochs RL, Stein TW, Peebles CL, et al. Autoantibodies in interstitial cystitis. J Urol 1994;151:587-92. 
7 Mahler M, Parker T, Peebles CL, et al. Anti-DFS70/LEDGF antibodies are more prevalent in healthy individuals compared to patients with systemic autoimmune rheumatic diseases. J Rheumato/ 2012;39:2104-10.

8 Dellavance A, Viana VST, Leon EP, et al. The clinical spectrum of antinuclear antibodies associated with the nuclear dense fine Speckled immunofluorescence pattern. J Rheumatol 2005;32:2144-9.
9 Bizzaro N, Tonutti E, Villalta D, et al. Recognizing the dense fine speckled/lens epithelium-derived growth factor/p75 pattern on HEp-2 cells: not an easy task! Comment on the article by Mariz et al. Arthritis Rheum 2011;63:4036-7.

10 Mahler M, Andrade LE, Casiano CA, et al. Implications for redefining the dense fine Speckled and related indirect immunofluorescence patterns. Expert Rev Clin Immunol 2019;15:447-8. 